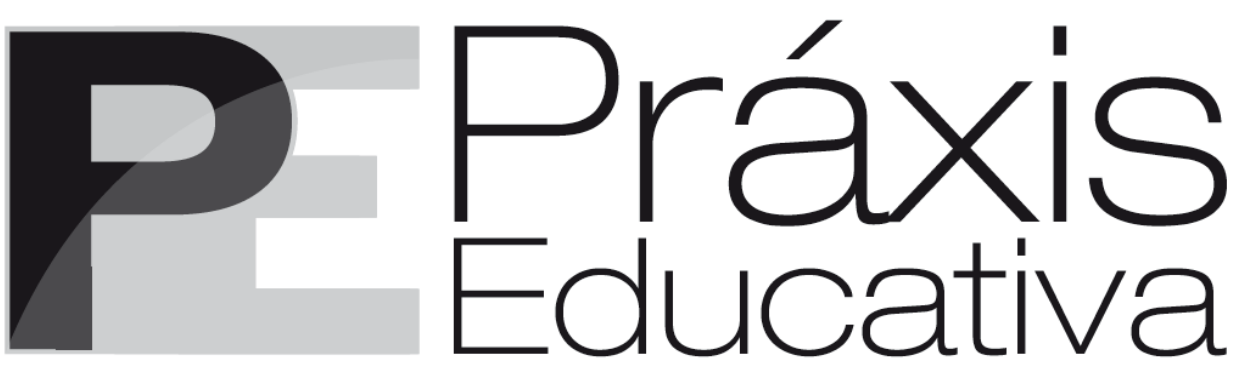

ISSN 1809-4031

elSSN 1809-4309

https://doi.org/10.5212/PraxEduc.v.15.16212.067

\title{
Tempos da escola em tempo de pandemia e necropolítica
}

\section{School times in a time of pandemic and necropolitics}

\section{Tiempos de la escuela en tiempo de pandemia y necropolítica}

\author{
Walter Omar Kohan* \\ https://orcid.org/0000-0002-2263-9732
}

\begin{abstract}
Resumo: O presente texto está inspirado em uma live apresentada junto à Maura Corcini, organizada pela Associação Nacional de Pós-Graduação e Pesquisa em Educação (ANPEd). Ele tem quatro seções. A primeira, "A necrologia, a pandemia, o Brasil", descreve a forma em que o governo bolsonarista desenvolve uma necropolítica, inclusive a partir da trágica pandemia do COVID-19 que, atualmente, se expande pelo Brasil e pelo mundo. A segunda, "A educação, entre a necropolítica e a pandemia", anuncia duas dimensões dessa mesma pandemia e o que ela nos permite perceber em relação à escola, como instituição e como forma. A terceira, "A pandemia e os tempos da escola", apresenta a especificidade de três tempos presentes na educação: khrónos, kairós e aión. Finalmente, a ultima seção, "O tempo da infância: Isabel(a) e o tempo imprevisível da leitura e da escrita", retoma uma inspiração infantil e alguns sentidos que dela emanam para lembrar do valor e do sentido da infância na educação.
\end{abstract}

Palavras-chave: Tempo. Escola. Necropolítica.

\begin{abstract}
The present text is inspired by a live presented with Maura Corcini, organized by the National Association of Graduate Studies and Research in Education (ANPEd). It has four sections. The first section, "The necrology, the pandemic, Brazil", describes the way in which the Bolsonarist government develops a necropolitics, including from the tragic COVID-19 pandemic that is currently expanding throughout Brazil and the world. The second section, "Education, between necropolitics and pandemic", announces two dimensions of this same pandemic and what it allows us to perceive in relation to school, as an institution and as a form. The third section, "The Pandemic and the school times", presents the specificity of three educational times: chronos, kairos and aion. Finally, the last section, "The time of childhood: Isabel(a) and the unpredictable time of reading and writing" resumes a childlike inspiration and some senses that emanate from it to remember the value and meaning of childhood in education.
\end{abstract}

Keywords: Time. School. Necropolitics.

Resumen: El presente texto está inspirado en una presentación en vivo con Maura Corcini organizada por la Asociación Nacional de Posgrado e Investigación en Educación (ANPEd). Tiene cuatro secciones. La

\footnotetext{
* Professor titular da Universidade do Estado do Rio de Janeiro (UERJ), pesquisador do Conselho Nacional de Desenvolvimento Científico e Tecnológico (CNPq) e da Fundação de Amparo à Pesquisa do Estado do Rio de Janeiro (FAPERJ). Coordenador do Projeto "Filosofia na Infância da Vida escolar" (CAPES-PrInt). E-mail: <wokohan@gmail.com>.
}

Práxis Educativa, Ponta Grossa, v. 15, e2016212, p. 1-9, 2020 Disponível em: <https://www.revistas2.uepg.br/index.php/praxiseducativa> 
primera, "La necrología, la pandemia, Brasill", describe la forma en que el gobierno bolsonarista desarrolla una necropolítica, incluso a partir de la trágica pandemia del COVID-19 que actualmente se está expandiendo por Brasil y por el mundo. La segunda, "La educación, entre la necropolítica y la pandemia", anuncia dos dimensiones de esta misma pandemia y lo que ella nos permite percibir en relación con la escuela, como institución y como forma. La tercera, "La pandemia y los tiempos de la escuela", presenta la especificidad de tres tiempos presentes en la educación: khrónos, kairós y aión. Finalmente, la última sección, "La época de la infancia: Isabel(a) y el imprevisible tiempo de la lectura y de la escritura", retoma una inspiración infantil y algunos sentidos que emanan de ella para recordar el valor y el sentido de la infancia en la educación.

Palabras clave: Tiempo. Escuela. Necropolítica.

À Isabel(a),
que me ensina tanto sobre ler e escrever

\section{Introdução}

Este texto é um texto de infâncias. Ele nasceu de uma apresentação em uma live junto à Maura Corcini, em 13 de maio de 2020, organizada pela Associação Nacional de Pós-Graduação e Pesquisa em Educação (ANPEd). Agradeço à Maura, pela inspiração e pela hospitalidade daquela tarde, e à Geovana Lunardi, presidenta da ANPEd, pelo convite para a live e, depois, para tornar aquela apresentação em um texto escrito para o presente Dossiê.

Quando estava tentando dar forma escrita aos rascunhos daquela tarde, sacudido pelas mortes pretas causadas pelo racismo que abala o Brasil, os Estados Unidos e o mundo, e pelas mortes causadas, em parte, pelo COVID-19 e, em parte, pela brutal irresponsabilidade do governo brasileiro, fui mexido pela inspiração decisiva que estava precisando de uma voz infantil. Compreendi que este texto não poderia apenas dar voz à gravíssima situação política e sanitária em que se encontra atualmente o Brasil, e que qualquer pensamento em torno da educação e da escola também deveria honrar a infância e a dimensão infantil do tempo que estamos vivendo e do tempo educacional que a infância pode nos fazer viver.

Com essa pretensão e inspiração, o texto está dividido em quatro partes principais. $\mathrm{Na}$ primeira, "A necrologia, a pandemia, o Brasil", descrevemos a forma em que a necropolítica do governo bolsonarista encontra na atual pandemia do COVID-19 uma extensão do seu modus operandi. Na segunda, "A educação, entre a necropolítica e a pandemia", anunciamos duas dimensões da pandemia e o que ela nos tem permitido perceber em relação à escola. Na terceira, "A pandemia e os tempos da escola", apresentamos a especificidade de três tempos presentes na educação. Finalmente, em "O tempo da infância: Isabel(a) e o tempo imprevisível da leitura e da escrita", retomamos a inspiração infantil e alguns sentidos para repensar a forma em que nos relacionamos com a infância na educação.

Já é hora de começar e apresentar a primeira inspiração infantil. Vem de uma fala de Isabel(a), menina açoriana de 9 anos: "Não é quando a gente quer que pode ir escrever. As palavras vão sair más se escrevermos sem disposição" . Obrigado, Isabel(a), pela preciosa dica: o tempo da escrita, efetivamente, não é o da nossa vontade, mas o de nossa disposição. Precisamos dispor-nos, inteiramente presentes, se não queremos que nossas palavras saiam más. Com essa disposição, presença e atenção infantis, começamos a escrever um texto que voltará à Isabel(a) e a sua voz infantil.

\footnotetext{
${ }^{1}$ Isabel(a), criança açoriana, de 9 anos, é filha da minha colega e amiga Magda e do Ricardo. Ela me autorizou a colocar assim seu nome, porque ela gosta. E também achou muito "gira" uma versão inicial do presente texto.
}

Práxis Educativa, Ponta Grossa, v. 15, e2016212, p. 1-9, 2020

Disponível em: < https://www.revistas2.uepg.br/index.php/praxiseducativa> 


\section{A necrologia, a pandemia, o Brasil}

Vivemos um momento muito difícil no Brasil. Uma guerra. Em certo sentido, a guerra não é nova pois faz parte do projeto colonizador imposto ao longo dos últimos séculos em toda a América. As comunidades indígenas, negras e, de forma mais geral, as mais empobrecidas que o digam. Trata-se de uma guerra permanente, constante, persistente, um projeto racista, misógino, assassino que se afana em excluir todas as formas da diferença que não se encaixam nele. O mais específico do atual momento brasileiro é a virulência dessa guerra, seu caráter ostensivo, brutal, exterminador, o que o nosso colega da Universidade do Estado do Rio de Janeiro (UERJ), João César Castro Rocha, denomina "a guerra cultural bolsonarista/olavista" (ROCHA, 2020, n.p.). Como Rocha mostra, o governo Bolsonaro vive da morte, do extermínio que fazem parte do seu modus operandi de maneira essencial. É a consumação da necropolítica baseada em um conceito de soberania, como o que A. Achile Mbembe afirma: "[...] a instrumentalização generalizada da existência humana e a destruição material de corpos humanos e populações" (MBEMBE, 2018, p. 10-11). Nesse sentido, Foucault tinha apresentado o trânsito do poder da soberania ao biopoder, por volta do século XVIII europeu, como um trânsito do mote do fažer morrer e deixar viver ao mote do fazer viver e deixar morrer (FOUCAULT, 2006, p. 285ss.). Entre os séculos XVII e XIX, consolidase a noção de população e, com ela, a de biopolítica. Autores como G. Agamben e o próprio Mbembe têm descrito a passagem mais contemporânea do império da biopolítica (do grego bios = vida) à necropolítica (do grego nékros = morte). Essa passagem talvez corresponda a um movimento recente nas sociedades europeias: de nosso lado do mundo, estamos já instalados na necropolítica desde a chegada dos europeus. O que é a necropolítica? Digamo-lo de forma simples, com a inspiração de M. Foucault: entre nós, a necropolítica é um dispositivo de governo para faz̧er morrer e não deixar viver.

O momento atual é elucidativamente cruel. A pandemia gerada pelo COVID-19, longe de ser combatida firmemente, está sendo veiculizada como mais um instrumento dessa necropolítica, quase como uma oportunidade de consolidar a política da morte de forma mais rápida, segura, econômica. O bendito "mercado" tem dado sinais mais do que claros nesta primeira semana de junho de 2020: a mesma semana em que o Brasil bateu recorde de mortes, ultrapassando os 35 mil mortos ${ }^{3}$; o real valorizou-se quase $7 \%$ frente ao dólar; a bolsa de valores de São Paulo subiu mais de $8 \%$; "os mercados mostram sinais de recuperação", anunciam os jornais. Há necessidade de dados mais claros para ver a aliança entre a versão local do capitalismo e a necropolítica? Se houver alguma dúvida, basta escutar a Bolsonaro ainda nesta mesma semana (ou em qualquer outra): "A gente lamenta todos os mortos, mas é o destino de todo mundo" (2 de junho de 2020) ${ }^{4}$. Naturalizar e banalizar a morte faz parte da necropolítica. Antes, no começo da pandemia, o próprio tinha deixado ver antecipadamente o caráter higienista de sua necropolítica: "Vão morrer alguns [idosos e pessoas mais vulneráveis] pelo vírus? Sim, vão morrer. Se tiver um com deficiência, pegou no

\footnotetext{
${ }^{2}$ No dia 7 de junho de 2020, a guerra tornou-se também interna com o desabafo insultante de Olavo de Carvalho ao Jair Bolsonaro com um vídeo cheio de afrontas e insultos, postado nas redes sociais. Nas mesmas redes, ele voltou logo atrás. Disponível em: <https://www.poder360.com.br/midia/olavo-rompe-com-bolsonaro-ameaca-derruba-loe-depois-volta-atras/>. Acesso em: 8 jun. 2020.

3 Painel COVID-19 do Ministério da Saúde. Disponível em: <https://covid.saude.gov.br/>. Acesso em: 5 jun. 2020. Nos últimos três dias, o Ministério da Saúde atrasou os dados. Dia 5 de junho, logo depois de colocar os dados diários, o portal entrou "Em manutenção" e o ministério da saúde emitiu nota dizendo que iria recontar casos porque afirma que há "dados fantasiosos". Faltou dizer de quem é a morbosa fantasia. Sobre as cotações do dólar, ver bcb.gov.br; sobre as cotações da Bolsa de São Paulo, ver <http://www.bmfbovespa.com.br/pt_br/servicos/marketdata/cotacoes/>. Acesso em: 16 jun. 2020.

${ }^{4}$ Disponível em:

<https://www.correiobraziliense.com.br/app/noticia/politica/2020/06/02/interna_politica,860325/a-gentelamenta-todos-os-mortos-mas-e-o-destino-diz-bolsonaro.shtml>. Acesso em 16 jun. 2020.
}

Práxis Educativa, Ponta Grossa, v. 15, e2016212, p. 1-9, 2020 Disponível em: < https://www.revistas2.uepg.br/index.php/praxiseducativa> 


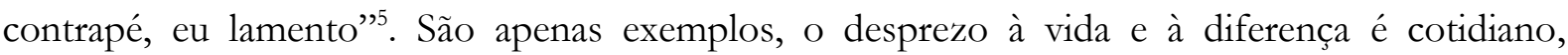
insultante, abominável. Hoje morre uma pessoa por minuto pelo vírus no Brasil. Dolorosamente, quando este texto estiver sendo lido, os números da morte serão ainda mais impactantes. E, em uma sociedade racista e machista, já podemos antecipar quais serão os principais alvos da necropolítica.

Uma das coisas que Bolsonaro não diz é que, pelo seu cargo, ele deveria se ocupar, em um momento de pandemia, de gerar as melhores condições possíveis para que a morte não chegue desnecessariamente antes do tempo. Também não diz que uma boa parte dessas mortes poderiam estar sendo evitadas. A vizinha Argentina é, desta vez, um bom exemplo, quase oposto em termos de como o governo reagiu perante a pandemia. Se, no Brasil, o governo desde o início da pandemia insistiu em minimizar e desqualificar a importância do COVID-19 e que a economia não poderia parar; na Argentina, adoptou-se, desde março, um isolamento estrito nacionalmente. $O$ primeiro caso de COVID-19 identificado na Argentina foi no dia 3 de março, e a primeira morte foi anunciada em 7 de março. No Brasil, o primeiro óbito foi em 17 de março e, embora existam diversas versões sobre o efetivo primeiro caso no país, podemos considerar que os dois países receberam o COVID-19 em um período bastante próximo. Em 10 de junho de 2020, o Brasil tinha mais de 650.000 casos e mais de 35.000 mortes $^{6}$; a Argentina tem pouco mais de 21.000 casos e 632 mortes $^{7}$ - 30 vezes menos casos de infectados e... 50 vezes menos mortes! Mesmo que a população do Brasil seja quase cinco vezes maior do que a da Argentina, a diferença dos índices proporcionada é assustadora: no Brasil, há um índice de 167 mortes por milhão de habitantes; na Argentina, o índice é de 15 - 11 vezes menos o número de mortos em proporções relativas ao número de habitantes.

Ainda é preciso dizer mais alguma coisa? Talvez sim: estamos nos referindo à Argentina (não à Alemanha, à França, a Singapura, à Coreia do Sul ou ao Canadá), que tem uma crise econômica muito mais aguda do que a do Brasil e um sistema de saúde pública igualmente desatendido pelas políticas públicas dos últimos anos; e que os setores que governavam a Argentina, até final de 2019, responsáveis em boa parte por essa crise e essa desatenção da saúde pública, impulsam agora uma campanha contra o isolamento social, ao que chamam ironicamente de "infectadura", com argumentos semelhantes aos defensores da necropolítica no Brasil. ${ }^{8}$ Em outras palavras, se o vírus tivesse chegado o ano passado, talvez a Argentina estaria em uma situação não tão diferente da que o Brasil padece hoje: a necropolítica e o capital entre nós não têm nacionalidade ou atravessam todas elas.

\section{A educação, entre a necropolítica e a pandemia}

Nesse cenário, a educação no Brasil encontra-se encurralada entre a pandemia e a necropolítica. Enquanto assistimos a cenas de corpos apilhados nos hospitais e nos cemitérios das grandes cidades, alguém poderia perceber, com diferente grau de satisfação, a morte da própria escola. Com efeito, para os discursos mais conservadores e regressivos, a pandemia poderia ser uma oportunidade propícia para distancializar de vez a educação: se as práticas educativas podem

\footnotetext{
5 Disponível em:< https://noticias.uol.com.br/colunas/leonardo-sakamoto/2020/03/27/bolsonaro-querconvencer-que-vida-de-idoso-e-pedagio-a-pagar-ao-coronavirus.htm>. Acesso em 16 jun. 2020.

6 Dados extraídos do Conselho Nacional de Secretários de Saúde (CONASS), disponível em: <http://www.conass.org.br/painelconasscovid19/>. Acesso em: 10 jun. 2020.

7 Dados extraídos do Ministerio de Salud, República Argentina, disponível em: <https://www.argentina.gob.ar/coronavirus/informe-diario/junio2020>. Acesso em: 10 jun. 2020.

8 Ver, por exemplo, Los anticuarentena marcharam ao Obelisco, disponível em: <https://www.pagina12.com.ar/269259los-anticuarentena-marcharon-al-obelisco >. Acesso em: 6 jun. 2020.
}

Práxis Educativa, Ponta Grossa, v. 15, e2016212, p. 1-9, 2020

Disponível em: < https://www.revistas2.uepg.br/index.php/praxiseducativa> 
continuar a distância, qual seria a real necessidade de seguir mantendo escolas abertas com as pretensões explicitadas até o cansaço de ajuste nos gastos públicos? Para que manter uma instituição que vive em permanente crise, que exige recursos que poderiam ser usados com outros fins e que dá conta pifiamente de suas funções e sentidos sociais? Não deveríamos aproveitar o vírus e desescolarizar de vez a sociedade? ${ }^{?}$

A pandemia tem nos oferecido a possibilidade de pensar e de perceber as coisas de outra maneira. Eis a dupla cara do COVID-19: de um lado, ele infecta, contamina, atrofia, pelo menos temporalmente, alguns sentidos, principalmente o olfato e o paladar; também ataca sobretudo os pulmões, gerando a falta de ar que, em muitos casos, leva à morte. Ele é letal e, como todo vírus, vive da morte do corpo que o aloja. Ele é necrófilo. Contudo, ao mesmo tempo, ele tem suspendido um sistema que parecia inquebrantável, imparável, incontornável. Como o sistema que suspende também vive da morte, podemos dizer que, implicitamente, ele é também biófilo. Ao mesmo tempo, o vírus ama a morte e a morte da morte, a vida que pelo menos potencial e indiretamente libera. Um dos aspectos do sistema capitalista que tem sido suspendido pelo vírus é a experiência frenética, exigida, produtivista do tempo que esse sistema estimulava e da qual vivia. Voltaremos a essa experiência temporal.

Também seus efeitos sobre as escolas ${ }^{10}$ mostram a dupla cara do vírus: pela primeira vez desde sua existência, todas as escolas foram obrigadas a fechar de vez. Ficamos todos subitamente sem escolas, no Brasil e no mundo. Em um sentido, então, o vírus decretou uma morte, pelo menos temporariamente, das escolas: as deixou sem vida interna, sem cheiros, sabores, sem ar. Contudo, ao mesmo tempo, até os mais críticos da instituição escolar, pudemos perceber o que não percebíamos, pelo menos, com a clareza que a pandemia nos oferece, pois devemos também aceitar que a pandemia tem a potência de mostrar tudo mais claramente.

Notemos alguns dos principais aspectos relativos a essa escola que não percebíamos tão claramente e que esse tempo de pandemia nos tem mostrado com chamativa nitidez (a relação não é exaustiva): a diferença radical entre as escolas públicas e particulares e, de um modo mais geral, entre a educação pública e a educação privada; o tanto de coisas que se fazem em uma escola, que não dizem respeito a apenas ao ensinar e ao aprender, mas à dimensão social da escola em um país como o Brasil, onde, para muitos setores da população, a escola é o local onde se faz a principal (ou única) refeição do dia e que não há como fazer quando ela fecha as suas portas; a insubstituível presença de professoras e de professoras que não podem ser substituídos(as) por quem não está preparado para isso e menos ainda por sistemas tecnológicos auto programáveis e executáveis; a inescusável necessidade de formar os e as docentes atuantes nas escolas para que possam ser os e as docentes que desejam ser; as gritantes desigualdades da sociedade brasileira com uma altíssima parte da população sem as mínimas condições de conectividade e aparelhagem como para atender a uma educação remota ou a distância; a impossibilidade de se fazer escola sem corpos presentes, corpos que se tocam, se abraçam, se cheiram e até se empurram e se atropelam; a tensão entre a casa e a escola ou, em outras palavras, a importância de a escola ter um espaço próprio, separado, apartado das outras instituições sociais; ainda, em outras palavras, a impossibilidade de ser mãe e

\footnotetext{
9 A referência implícita a Iván Illich é explícita e deliberada. Recentemente, em "Razones para reivindicar a esa vieja vaca sagrada llamada escuela", Nicolás Arata lembra a intervenção de Iván Illich no Congresso Pedagógico Nacional Boliviano, em 1970, exortando os professores e as professoras bolivianos(as) a liberar a Bolívia de seu sistema escolar. A expressão "velha vaca sagrada" é do próprio Illich. Como esclarece Arata, muito longe dos interesses libertários de Illich, estão os que hoje querem aproveitar o momento para se livrar da escola. O texto de Arata está publicado na série "Pensar a Pandemia" do Observatorio Social del Coronavirus de CLACSO, disponível em: https://www.clacso.org/razones-para-reivindicar-a-esa-vieja-vaca-sagrada-llamada-escuela/. Acesso em: 10 jun. 2020. 10 O termo "escola" tem aqui um sentido genérico, abrangendo creches, escolas de Ensino Fundamental e Ensino Médio, universidades e qualquer outra forma de espaço pedagógico.
}

Práxis Educativa, Ponta Grossa, v. 15, e2016212, p. 1-9, 2020 Disponível em: <https://www.revistas2.uepg.br/index.php/praxiseducativa> 
docente, pai e docente ou filha/filho e aluno ao mesmo tempo. Como podemos perceber, não são poucas coisas as que o vírus tem permitido apreciar. E, mais uma vez, a lista está longe de ser exaustiva.

Em outras palavras, uma visão atenta aos efeitos da pandemia mostram, ao contrário do que as vozes que advogam pelo fim da escola querem concluir, o valor extraordinário e insubstituível da escola, como instituição histórica e social e, também, como forma de suspensão e de profanação (MASSCHELEIN; SIMONS, 2014), que permite aos que a povoam colocar o mundo sobre a mesa para colocá-lo em questão, entendê-lo, problematizá-lo e, quem sabe, imaginar e viver outros mundos. Vamos deter-nos em alguns aspectos específicos que a pandemia nos fez notar, em particular uma certa experiência do tempo e, também, uma especial relação com a infância.

\section{A pandemia e os tempos da escola}

Um dos efeitos principais provocados pela pandemia naqueles envolvidos em processos educacionais recai sobre nossa experiência do tempo. Certamente, ela nos afeta diferentemente e não pretendo simplificar algo tão complexo. Partirei de uma distinção primária entre os que atuamos na educação pública e os que atuam na educação privada. Naqueles submetidos às exigências de empresas dedicadas ao negócio educativo, a pandemia pode estar provocando uma sensação de vertigem ainda maior em função da necessidade de se adequar veloz e violentamente a uma situação em que "a empresa educativa" não pode parar. As cobranças continuam as mesmas, só que com efeito multiplicado pela dificuldade de um contexto para o qual ninguém estava preparado. Ao contrário, em aqueles que trabalhamos na educação pública, e mais especificamente nas universidades que suspenderam suas atividades de ensino, a pandemia provoca uma desaceleração e até uma suspensão da experiência do tempo educativo pela possibilidade de repensar os sentidos e as condições do que se faz. Explicitaremos mais amplamente essa ideia.

Com efeito, para os que temos o privilégio (que deveria ser um direito) de manter o isolamento social, a pandemia gera a sensação do mundo ter se detido. Para os que ficamos em quarentena, isso significa uma experiência de tempo suspenso, como se ele não passasse ou como se sua passagem tivesse efeitos relativamente pouco relevantes em função da detenção do mundo exterior. Efetivamente, estávamos habituados a pautar o que fazíamos em casa aos compromissos fora de casa; todavia, quando o fora de casa para, o tempo em casa fica liberado dessa pressão. Esse efeito é muito semelhante ao que Masschelein e Simons (2014) chamam de "suspensão": na escola, enquanto forma escolar, o que vale fora da escola está suspenso para que a escola possa fazer as suas operações pedagógicas. Por isso mesmo, eles argumentam que a escola nasce simbolicamente quando ela fecha as suas portas, porque ela vive da separação, da suspensão do que vale socialmente. Nesse sentido, seria impossível pensar uma escola-casa ou uma escola em casa, pois justamente a escola nasce da separação da casa e das outras instituições sociais.

Lembremos que a palavra escola tem na sua raiz etimológica uma palavra grega, skeholé, que significa justamente "tempo livre", no sentido de tempo liberado das exigências extraescolares. Nessa dimensão, enquanto dure a quarentena - e "suspendendo" também por um momento a radical distinção de Masschelein e Simons entre escola e casa -, nossa experiência do tempo tornase escolar, no sentido de estar liberada das exigências habituais do mundo de trabalho. Nesse sentido, curiosa e paradoxalmente, aqueles submetidos às pressões de instituições educativas privadas viram-se impedidos de experimentar um tempo escolar pelo mercado educativo escolar. Nesse mesmo sentido, vale perceber que os que fazem negócio com a escola negam a escola pois negócio vem do latino neg-otium, sendo otium um equivalente latino de skholé, tempo livre. Quem faz

Práxis Educativa, Ponta Grossa, v. 15, e2016212, p. 1-9, 2020

Disponível em: < https:/ /www.revistas2.uepg.br/index.php/praxiseducativa> 
neg-otium, negócio, faz de fato uma anti-escola, negam o que a escola é, tempo liberado. A pandemia também permite apreciar isso com maior claridade.

Uma compreensão mais específica do tempo experimentado na pandemia exige-nos uma exploração mais detalhada de sentidos possíveis da experiência temporal. Nesse marco, faz algum tempo que temos trabalhado a diferença entre três formas de temporalidade que vêm da Grécia antiga: khrónos, kairós e aión (KOHAN, 2004). Apresentemo-las novamente de forma sucinta e mais atenta ao tema que aqui estamos abordando: khrónos é o tempo de relógio, do calendário, da instituição. É o tempo que não para, que segue movimentos uniformes, sucessivos, consecutivos, irreversíveis, qualitativamente indiferenciados. É um tempo composto de duas partes (passado e futuro) e uma terceira que apenas tem a materialidade de um limite entre as outras duas: o presente em khrónos é apenas o instante, o agora. Kairós é o tempo da oportunidade, o momento oportuno, a ocasião adequada para se experimentar algo como não se poderia experimentar em qualquer outro momento; é um tempo qualificado, preciso, singular, único. Aión é a duração no tempo; o tempo intensivo, da experiência, do acontecimento. Ele é puro presente. É o tempo daquelas experiências que nos fazem sentir que o presente dura, nas quais estamos como suspendidos no presente: a arte, o amor, a filosofia e, pensando na escola, a leitura, a escrita, o estudo.

Essas três formas de experiência temporal têm importância singular na educação: khrónos é um tempo adulto: o tempo do sistema educativo, das instituições educacionais, da organização do trabalho pedagógico. Tudo o que acontece nas escolas contemporâneas é regido por khrónos: os níveis de ensino, as planificações docentes, a sequência curricular... e a importância de khrónos para a vida social é uma das principais coisas que ensina a instituição escolar, desde a creche até a universidade: as crianças entram nas creches no seu tempo aiónico e saem adultos adequadamente cronologicados.

Por sua vez, kairós também é um tempo adulto: o cruzamento coincidente entre os tempos da inscrição das pessoas no sistema educativo e de certas experiências pedagógicas. É um tempo de coincidência que, por uma imensa variedade de condições, pode ou não acontecer. O sistema e as instituições que seguem khrónos estabelecem idades, fases e momentos para certos processos pedagógicos, organizam os e as estudantes cronologicamente. Por sua vez, as pessoas que dele participam têm suas histórias de vida, culturais, afetivas, pessoais. Desse cruzamento resultam experiências pedagógicas oportunas e inoportunas. Muitas vezes, é o próprio sistema que expulsa e impossibilita o acesso dos estudantes ao processo de aprendizagem no momento que para elas seria propício, oportuno; outras, é a professora ou professor ou a própria estudante que não oportunizam esse momento. As crianças sentem a dificuldade de oportunizar seu tempo da maneira em que ele é disposto pela instituição escolar. Finalmente, aion é o tempo infantil. Precisamente, aión é o tempo da experiência educativa enquanto tal, do perguntar, do querer saber, do amar pensar, do criar, do brincar como modo de habitar o mundo... é o tempo da educação como uma experiência durativa, intensiva, que prolonga a temporalidade presente: o acontecimento que interrompe a sequência cronológica e permite uma experiência que se faz presencial, em tempo presente. É o trabalho docente como presença no presente, durativo, intensivo.

O tempo que a pandemia mais afeta a primeira vista é a experiência de khrónos. É claro que a pandemia não afeta khrónos enquanto tal, pois os relógios continuam passando ao mesmo ritmo, com ou sem pandemia. Contudo, nossa experiência cronológica, nossa relação com o tempo do relógio (ou do celular) tem sido profundamente alterada. Para alguns, submetidos a uma exigência ainda maior que antes da pandemia, ele se tornou mais voraz e frenético. Para outros, ele desacelerou. A maior ou menor medida na passagem de khrónos traz como consequência possibilidades ou impossibilidades de experimentar as outras formas da temporalidade. Quanto mais estressados e atormentados pelas demandas em khrónos, menos tempo para pensar, assistir um

Práxis Educativa, Ponta Grossa, v. 15, e2016212, p. 1-9, 2020 Disponível em: < https://www.revistas2.uepg.br/index.php/praxiseducativa> 
filme ou brincar com qualquer coisa. Não me refiro apenas a menos tempo cronológico, mas também a menos condições de experimentar um tempo de oportunidade e intensidade. Nesse sentido, talvez seja tempo de voltar à infância, não a nossa infância cronológica, mas, sim, ao nosso tempo de infância, aquele que vivemos quando crianças cronológicas e que como educadores temos sido capazes de manter vivo, cultivar e cuidar, como fazia um tal Paulo Freire, que recebeu entre tantos outros prêmios e reconhecimentos, o de "bambino permanente" (menino permanente) quando tinha 69 anos de idade ${ }^{11}$. Quem sabe a inspiração venha de uma criança, de uma infante cronológica que vive um outro tempo de educação. Escutemos.

\section{O tempo da infância: Isabel(a) e o tempo imprevisível da literatura}

Voltemos a Isabel(a). Com ela, compartilhamos, nesta pandemia, algumas conversas e uma conversa com outras crianças açorianas e brasileiras. Durante a pandemia, Isabel(a) teve sua experiência educativa continuada por via remota. Faz algumas semanas, ela estava muito braba com o seu professor de literatura. Qual a razão? O professor tinha pedido para ela fazer a leitura de um livro com data marcada. Havia um prazo para ler, tinham de ler o livro até uma terça-feira e isso, (só isso!), revoltava Isabel(a): "como é possível?!”, ela se queixava. E acrescentava: "a leitura é imprevisível". A palavra im-pre-visível é muito expressiva. Literalmente significa "não antes ver", poderíamos dizer: não ver antes de ver, não antecipar antes de ver, não ler antes de ler. Ou de modo afirmativo: ler quando lés, ler lendo, ler submergida na leitura, ler sem fazer nenhuma outra coisa além de ler. Quando se lê dessa maneira, não há como fixá-la a prazos ou a nenhuma outra temporalidade que não seja a aiónica. O dispositivo de acomodar a leitura aos modos de khrónos, como se faz na escola e como fez o professor de Isabel(a), pode ter efeitos interessantes, mas de algum modo violenta à experiência da leitura. É contra essa violência que reage Isabel(a).

Assim, a anedota, simples, singela, é também muito ilustrativa de duas formas de relação com o tempo que não se limitam apenas a essa anedota. Nesse caso, o professor, preocupado com as exigências curriculares da instituição, está habitando khrónos, e a ele remite uma atividade de leitura a essa temporalidade. Só que Isabel(a) habita outro tempo e relaciona a leitura com outro tempo, aión, um tempo de presença e presente, de experiência e, portanto, infindável, imprevisível... impossível de ser submetido aos ditados quantitativos de khrónos. Essas duas formas de relação com o tempo dão marco também a duas formas de relação com a leitura (e também com a escrita e com tantas outras coisas). Uma pergunta que não quer calar é: Qual é mais rica, interessante e, sobretudo, educativa?

Não precisamos responder a essa pergunta. Ela talvez seja exageradamente adulta, como o tempo que habitamos enquanto professores. Deixemo-la a um lado e demos voz a uma outra pergunta, muito mais infantil, vindo da mesma Isabel(a): "Por que é que os professores têm de saber se nós compreendemos ou não? Se nós compreendemos é conosco. Os professores não têm que meter o nariz onde não são chamados", Pois é, Isabel(a), isso mesmo. Pode tratar-se desse mesmo professor ou de qualquer um. Pode tratar-se de literatura ou de qualquer outra matéria. Trata-se, de certo modo, de entender e praticar a educação. Aqui já não é, apenas ou sobretudo, questão de tempo. Parece tratar-se de algo diferente: de uma questão de poder, de controle, de disciplinamento. Alguns adultos não apenas limitam a experiência escolar infantil ao submetê-la a um tempo alheio, empobrecedor; eles também exercem um poder que corrói a relação das crianças com o conhecimento, que clama, na voz de Isabel(a), por maior liberdade. Adultos metem o nariz em um mundo infantil ao qual não foram chamados, e a infância resiste essa pretensão.

\footnotetext{
${ }^{11}$ O prêmio foi outorgado pela Biblioteca Comunale di Ponsacco, em Pisa, Itália, em 31 de março de 1990 (KOHAN, 2019).
}

Práxis Educativa, Ponta Grossa, v. 15, e2016212, p. 1-9, 2020

Disponível em: < https://www.revistas2.uepg.br/index.php/praxiseducativa> 
Mais um pouco de Isabel(a): como tantas crianças no mundo inteiro, passou por diversas oscilações de ânimo durante os dias de escola remota, alternando momentos de alegria quando encontrava seus colegas e professores na tela, mas também outros momentos de mais tristeza, choro, recolhimento quando sentia sua falta. O porquê desses sentimentos é comum a tantas crianças que ouvimos nesses dias: a saudade dos amigos e das amigas, dos abraços, dos risos, dos beijos, das brincadeiras que só se podem realizar em uma relação de corpo a corpo. É que a escola é também isto: um lugar onde os corpos se encontram para brincar e fazer amigas e amigos, ou seja, um lugar onde se faz comunidade, se compartilha um mundo com todas as suas penúrias, belezas e dificuldades. A escola é também um espaço onde os amigos e as amigas, com ajuda de professores e de professoras e, junto a elas, estudam, leem, escrevem, pensam, questionam esse mundo. Eis uma segunda aprendizagem vinda da Isabel(a): há uma dimensão da escola insubstituível na construção de uma comunidade que busca compreender, problematizar e reinventar o mundo. Para isso, os professores e as professoras podem pretender impor um tempo e seus poderes e modos de conhecer ou estar atentos e sensíveis aos tempos, poderes e modos de conhecer infantis.

Eis que chegamos ao fim de nosso texto: abraçando a força inventora de inícios da infância. Entre a pandemia, a necropolítica e a instituição escolar assoma com toda a sua potência, beleza e vitalidade uma voz infantil. Dessa forma, a escuta às palavras de Isabel(a) é um gesto que, quem sabe, talvez possa inspirar uma outra forma, infantil, de fazer escola, um outro tempo para experienciar a vida escolar. É apenas questão de nos abrir à infância, de aprender de sua forma de sentir o tempo, a leitura, a escrita, o pensamento... e de não esquecer de cuidar, de cuidar sempre, de permanecer sempre cuidando, a qualquer idade, a nossa vida infantil, em especial quando habitamos uma escola.

\section{Referências}

FOUCAULT, M. Em defesa da sociedade. São Paulo: Martins Fontes, 2006.

KOHAN, W. O. A infância da educação. O conceito "devir-criança”. In: KOHAN, W. O. (org.) Lugares da infância: filosofia. Rio de Janeiro: DP\&A, 2004. p. 51-68.

KOHAN, W. O. Paulo Freire mais do que nunca: uma biografia filosófica. Belo Horizonte: Vestígio, 2019.

MASSCHELEIN, J.; SIMONS, M. Em defesa da escola: uma questão pública. Belo Horizonte: Autêntica, 2014.

MBEMBE, A. Necropolítica: biopoder, soberania, estado de exceção, política da morte. Tradução de Renata Santini. São Paulo: N-1 edições, 2018.

ROCHA, J. C. C. Guerra cultural e retórica do ódio: crônicas do Brasil. Rio de Janeiro: Caminhos, 2020. No prelo.

Recebido em 30/05/2020

Aceito em 20/06/2020

Publicado online em 23/06/2020

Práxis Educativa, Ponta Grossa, v. 15, e2016212, p. 1-9, 2020

Disponível em: < https://www.revistas2.uepg.br/index.php/praxiseducativa> 